\title{
Patient with Allergic Pathology: How to Handle It inDentistry.
}

\author{
Cristina Salgado-González ${ }^{1}$, Marta Muñoz-Corcuera ${ }^{2}$, Jorge A. Cano-Durán ${ }^{1}$, \\ Melissa Rigesti-Fertonani ${ }^{1}$, Cécile Deschamps ${ }^{3}$, Víctor Cortezo Vidal ${ }^{1}$, Carmen \\ Martín Carrera-Presas ${ }^{2}$, Lorenzo De Arriba-De La Fuente ${ }^{4}$, Víctor M. Paredes- \\ Rodríguez, \\ ${ }^{1}$ Dds. Oral Medicine Postgraduate. Faculty Of Odontology Of The Complutense University Of Madrid. Spain. \\ ${ }^{2}$ Phd. Oral Medicine Postgraduate. Faculty Of Odontology Of The Complutense University Of Madrid. Spain \\ ${ }^{3}$ graduated In Dentistry. Faculty Of Odontology Of Lion 1, France. \\ ${ }^{4}$ Dds, Phd. Master Degree Program In Oral Surgery And Implantology. Honorary Professor In The Department \\ Of Medicine And Orofacial Surgery. Faculty Of Odontology Of The Complutense University Of Madrid, Spain.
}

\begin{abstract}
One of the most common medical emergencies that can occur in the appointment is an acute allergic reaction.The various forms of systemic allergicreactions are very well defined. These clinical situations are rarely described in the specialized literature and, in turn, poorly understood. Oral atopy comprises a wide variety of symptoms and signs sometimes difficult to differentiate from other adverse reactions. It is important to know the dental materials and other substances of stomatological use causing clinical diseases presented in oral mucosa; it corresponds to Stomatology Specialist his knowledge for diagnosis and successful treatment.
\end{abstract}

Keywords: allergies, dental consultation, treatment, emergencies.

\section{Introduction}

Due to the high prevalence of allergies in the dental office, it is very important to know how the physiological mechanism works, and what are the most characteristic signs and symptoms:

- Identify patients with a true allergic history. Knowing how to recognize the acute medical emergencies that can occur in the consultation, and know how to prevent them.

- Recognize changes in soft tissue that may be caused by an allergic reaction.

- Identify and plan appropriate dental treatment for patients with severe immune system disorders, whether by radiation, pharmacological treatments or immunodeficiency's.

- Recognize the signs and symptoms typical of allergic reactions.

\section{Material And Methods}

To carry out this work, we started looking for articles about PUBMED post-2010 with the following keywords: allergies, pathology of allergies, dental consultation, emergencies. Only items in English or Spanish were considered. The main exclusion criterion is the animal and / or in vitro study. This search resulted in a total of 152, 235 articles, respectively. Subsequently, the articles were selected according to the title and abstract. We arrived at a total of 8 items. Finally, we have selected some of the articles mentioned in the bibliography of some previously found articles that seemed important, although they were published before 2010 . We also chose to use a book. We have reached a total of 10 references.

\section{Epidemiology}

\section{Results And Discussion}

Allergy is an abnormal or hypersensitive response to a substance introduced into the body. In Spain, allergic pathology accounts for 3-5\% of Primary Care consultations [1].Allergic reactions account for about 6\% to $10 \%$ of adverse drug reactions. The risk of having an allergic reaction when given a drug is $1 \%$ to $3 \%$. Fatal drug reactions occur in approximately $0.01 \%$ and $0.1 \%$ of patients [1].Drugs are the most common cause of urticarial reaction in adults, and food and infections are the most common in children [1].About 5\% to $10 \%$ of people receiving penicillin will have an allergic reaction, and anaphylactic reaction to the drug will occur in $0.04 \%$ to $0.2 \%$ of these. $10 \%$ of people who experience an anaphylactic reaction may die, which represents 400 to 800 deaths per year [1].The most common causes of death from anaphylaxis are: penicillin, and wasp stings. Patients with no history of allergies are more likely to die from anaphylaxis than are allergic patients [2,3].In some cases, it has been seen that both antihistamines and toothpaste dyes could cause urticarial [1].Parabens used as preservatives in local anaesthetics have also caused anaphylactic reactions. Sulphites used in anaesthetic solutions to prevent the oxidation of vasoconstrictors can cause severe allergic reactions. The groups most susceptible to allergic reactions caused by sulphites are the patients who have been diagnosed with asthma [4]. 
In our country, asthma affects $11 \%$ of children between six and seven years of age, $9 \%$ of adolescents between 13 and 14 years of age and 5\% of adults are more prevalent in women than in men [5].Allergy to latex occurs between $1 \%$ and $6 \%$ of the general population, and much more commonly in people who have spina bifida [4]. Between $5 \%$ and $18 \%$ of health care providers are hypersensitive to latex [1].

\section{Aetiology}

Allergic diseases are disorders due to an immune reaction to a non-infectious foreign substance (antigen). They are a series of repeated reactions to a substance. These reactions involve different immunological hypersensitivities and elements of the nonspecific and specific branches of the immune system [6].Reactions involving the humoral system often appear more often after meeting the antigen; There are three types of hypersensitivity reactions (types I, II and III) involving elements of the humoral immunity system. Type IV hypersensitivity reactions involve the cellular immune system. Allergic reactions that involve the cellular immune system often have a delay in onset [6] (Table 1).

\section{Complications And Oral Manifestations}

\section{Type I Hypersensitivity}

Oral lesions may occur due to type I hypersensitivity reactions [1].In or around the oral cavity an atopic reaction can occur to different foods, drugs or anesthetics that are usually characterized by swelling of urticaria or angioedema. The reaction is generally fast, and develops in a short period after contact with the antigen. This painless inflammation of the soft tissues is produced by transuded of the surrounding vessels that can cause itching and burning [1].

\section{Type III hypersensitivity}

Foods, drugs or agents that are placed (in contact with oral cavity?) inside the oral cavity can cause white, erythematous or ulcerous lesions, type III hypersensitivity or an immune complex reaction [1]. These lesions develop quite rapidly, usually within a 24-hour period, after contact with the antigen occurs. Some cases of aphtha's stomatitis may be caused by type III hypersensitivity, but most are related to lymphocytic dysfunction [1].

\section{Type IV Hypersensitivity}

Contact stomatitis is a delayed allergic reaction that is associated with the cellular immune response in most cases. Due to the delayed nature of the reaction after contact with the allergen, the dentist should ask about contacts with materials that have occurred 2-3 days before the onset of the lesion [1].The antigen can be found in dental materials, toothpaste, mouthwashes, lipsticks ... Before using any of these materials, the dentist can perform tests to see if the patient has any incompatibility with them [1].

\section{Lichenoid Reactions}

Lichenoid reactions (RL) may involve the mucosa on the skin, or both [7].RLs are less common than lichen. These occur more in adult patients, and very rarely in children. The interval between the onset of drug use and the development of the lesions may range from weeks to months, with an average time of 2-3 months. Delayed onset reactions may be more than 1 year [7].Therefore, it is not easy to establish a temporal relationship between the use of the drugs, and the onset of the lesions. It is important to make a complete history, with medicines taken in the last 12-24 months. The lesions present may be reticular white papules, or erythematous erosions, depending on the drug involved, and may be associated with oral pain. The locations of lesions' locations are usually the same as in lichen, but only unilateral [7].RLs are associated with many systemic drugs, the most common of which are NSAIDs, antihypertensive and antiretroviral [7, 8].The RL are histologically indistinguishable from lichen planus, in both we can see hyperkeratosis, hydropic degeneration of the basal epithelial layer and inflammatory band infiltrate in the dermis [7].The treatment of RL consists in the interruption of the suspicious medication and the substitution by another drug. Injuries usually resolve, within weeks or a few months of withdrawing medication. Erosive lesions may persist, in addition to removing the medication, topical corticosteroids will be necessary $[7,8]$.

\section{Signs and symptoms}

The most frequent signs and symptoms are summarized in Table 2.

\section{Medical treatment}

Patients with atopy may receive injections so that they gradually become desensitized and are no longer allergic to the antigen [1]. 
The newest antihistamines are highly effective and produce fewer adverse effects [1].All patients with out-ofhospital anaphylactic reaction should be transferred to the hospital by ambulance. Initially, the action of any causative agent must be stopped [9,10].A brief history of exposure to the potential allergen should be obtained and promptly assessing the extent and severity of the reaction, including controlling vital signs and actively seeking signs of upper airway edema, bronchospasm, and circulatory shock. With the patient in supine position, administer oxygen, adrenaline and fluids as main treatment, to stabilize the cardiorespiratory state. Until this has been achieved, antihistamines and steroids play no role; even then, its usefulness is debatable [10].

\section{Oxygen and airway permeability}

Give oxygen and seek saturation above $92 \%$. The patient should be in the supine position, preferably with the legs elevated to optimize the venous return. Raise the head and torso to lessen respiratory distress. Request urgent assistance from anesthesia services if there are signs of airway obstruction [10].Cyanosis and exhaustion indicate imminent respiratory arrest. In this case, sedatives or muscle relaxants will be administered [10].

\section{Adrenalin}

Adrenaline is the drug of choice for acute anaphylaxis, both allergic mediated by $\operatorname{IgE}$ and non-allergic. Adrenaline should be administered to all but the most trivial cases, and only if there is progressive airway edema, bronchospasm or hypotension [10].It has beneficial $\alpha, \beta 1$ and $\beta 2$ adrenergic effects that counteract vasodilation, mucosal edema and bronchospasm [10].Another crucial role of adrenaline through adrenergic receptors of $\beta 2$ is to trigger an increase in intracellular cyclic AMP that inhibits the further release of mediators from mast cells and basophils, thus attenuating the severity of the reaction when adrenaline is given early [10].The doses of adrenaline IM, and IV depending on whether the patient is an adult or child are summarized below (Table 3).

\section{Second-line agents}

Once oxygen, epinephrine and fluid have been administered to optimize the cardiorespiratory state and tissue oxygenation, we could use other second-line agents as support [1].Antihistamines are second-line agents; The evidence supporting its use is weak [1].This option should be reserved primarily for symptomatic treatment of cutaneous involvement such as urticaria, mild angioedema and pruritus. They are not used as a single therapy in cases of severe anaphylaxis [10].The combination of $\mathrm{H} 1$ and $\mathrm{H} 2$ antihistamines better attenuates cutaneous manifestations of generalized allergic reaction than an $\mathrm{H} 1$ antagonist alone. However, there are no data in severe cases and their use in combination remains controversial. In addition, a non-sedating $\mathrm{H} 1$ antihistamine should be selected for patients upon discharge from hospital, especially if they wish to continue working or driving a vehicle [1].

\section{Tracing}

The clear majority of patients are discharged after a period of observation. In some cases, medication is prescribed as the auto injectable adrenaline, and in addition they are referred to specialist's allergists [10].

\section{Diagnostic tests}

The dentist may choose to refer the patient to an allergist for evaluation and testing, which are usually skin tests and provocation tests (PP).Skin tests are examinations that are used to identify the allergens that trigger a patient's allergic reactions. They are used to evaluate IgE-mediated responses and cellular responses [1].Challenge Tests: These are tests that explore cell hypersensitivity reactions. It is triggered by the activation of T lymphocytes by interacting with the antigenic determinant in the membrane of the antigen presenting cells. They are used both to determine contact dermatitis and late reactions to medications [1].Tests for allergy to local anesthetics are of little benefit because false positives are very common. Therefore, the allergist should also perform PP $[1,9]$.The oral epimucosa test in contact stomatitis involves placing the suspended antigen in contact with the oral mucosa and observing any reaction over a period of several days (eg, erythema, detachment, ulceration) that could indicate an allergy to the material test. In most cases, a reaction is not to be expected for at least 48 to 72 hours [1].

\section{Dental treatment protocol:}

Local anaesthetics:The most frequently associated reaction is a toxic reaction, which is not a true allergic reaction [1].The signs and symptoms of a vasoconstriction reaction are: tachycardia, apprehension, sweating and hyperactivity [1].The protocol of action will be as follows [1]:

1. In case of toxic reaction, explain the nature of the reaction and avoid injecting the anaesthetic solution via i.v. Sucking before injecting and limiting the dose to the recommended. 
2. If the history of the patient supports the existence of syncope and not of a toxic or allergic reaction, it will be necessary to try to reduce the anxiety during the consultations.

Procaine is the local anesthetic that causes the most allergic reactions. It has been seen that cross-reactivity exists between lidocaine and procaine; Related to the presence of methylparaben, which was previously used in small amounts as a preservative and is chemically like PABA. Methylparaben has ceased to be used, so this is no longer a problem [1].

Penicillin:Patients who have a history of allergy to penicillin should be given either erythromycin or clindamycin (150-300 mg every 6 hours) to treat their oral infections, or for prophylaxis of endocarditis $(600 \mathrm{mg}$ 1 hour earlier).In addition, we must know that in allergic patients, drugs that can cross-react [1].

Cephalosporin's are often used as an alternative to penicillin's; however, $10 \%$ of patients allergic to penicillin will also react with cephalosporin's [1].

Analgesics:The dentist must be aware of the multiple analgesic preparations containing aspirin or other salicylates. These agents should be avoided in the patient with adverse reactions associated with aspirin or other salicylates [1].

Rubber products:Latex allergy may manifest as anaphylaxis during a procedure dental care when the patient or dentist has been sensitized to it, o minimizes these adverse reactions, we must use nitrile [1].

Dental materials and products:It has been described that various dental materials and products can cause Type I, III, and IV hypersensitivity reactions. Topical anesthetics produce Type I reactions in the form of urticarial swelling. Mouthwashes and toothpastes containing phenolic compounds, antiseptics, astringents and flavoring agents can produce type I hypersensitivity, type III and type IV that affect the oral mucosa or the lips [1].

1. Printing materials containing an aromatic sulfonated catalyst produce delayed allergic reactions in postmenopausal women [1].

2. The acrylic monomer used in the construction of the complete dentures has caused some allergic reaction; However, the clear majority of changes due to prostheses are due to trauma or to secondary bacterial or fungal infections [1].

3. Metallic ions from some restorations are released because of the corrosion process of the materials, and penetrate hard and soft tissues causing local and general symptoms or both. These allergies occur when undergoing an ionization process that is facilitated by the contact of this with biological fluids.

4. The extent depends on $\mathrm{pH}$, saliva, temperature... [7].

The table below summarizes the types of treatments and the main characteristics of oral lesions per the type of hypersensitivity (Table 4).

Modifications in dental treatment planning

Most allergic patients can receive any treatment, if antigen 1 is avoided.

Figures and tables

\begin{tabular}{|c|c|c|c|c|c|}
\hline Hypersensitivity & Name & $\begin{array}{l}\text { Immune } \\
\text { component }\end{array}$ & $\begin{array}{c}\text { Effector } \\
\text { mechanisms }\end{array}$ & $\begin{array}{l}\text { Associated } \\
\text { alterations }\end{array}$ & Antigen \\
\hline TYPE I & $\begin{array}{c}\text { Allergy } \\
\text { Immediate }\end{array}$ & $\operatorname{IgE}$ & $\begin{array}{c}\text { Mast cells, } \\
\text { basophils and } \\
\text { soluble mediators } \\
\text { produced by these } \\
\text { cells }\end{array}$ & $\begin{array}{c}\text { Atopia } \\
\text { Anaphylaxis } \\
\text { asthma }\end{array}$ & $\begin{array}{l}\text { Soluble proteins, } \\
\text { allergens. }\end{array}$ \\
\hline TYPE II & $\begin{array}{l}\text { Dependent } \\
\text { antibody }\end{array}$ & IgG & $\begin{array}{l}\text { Complement, } \\
\text { ADCC }\end{array}$ & $\begin{array}{c}\text { Thrombocytope } \\
\text { nia } \\
\text { Hemolytic } \\
\text { anemia } \\
\end{array}$ & $\begin{array}{c}\text { Tissue or cell } \\
\text { surface antigens }\end{array}$ \\
\hline TYPE III & $\begin{array}{l}\text { Immune } \\
\text { complex } \\
\text { disease }\end{array}$ & IgG & $\begin{array}{c}\text { Complement, } \\
\text { ADCC, } \\
\text { inflammatory cells }\end{array}$ & $\begin{array}{l}\text { Systemic lupus } \\
\text { erythematosus }\end{array}$ & $\begin{array}{c}\text { Bacterial } \\
\text { polysaccharides, } \\
\text { proteins }\end{array}$ \\
\hline TYPE IV & $\begin{array}{c}\text { Delayed } \\
\text { hypersensitivity }\end{array}$ & $\begin{array}{c}\text { Proinflammator } \\
\text { y cytokines }\end{array}$ & $\begin{array}{c}\text { Activated } \\
\text { macrophages }\end{array}$ & $\begin{array}{c}\text { Contact } \\
\text { Dermatitis. } \\
\text { Multiple } \\
\text { sclerosis } \\
\end{array}$ & Metals, latex, ... \\
\hline
\end{tabular}

Table 1. Types of hypersensitivity reactions. 


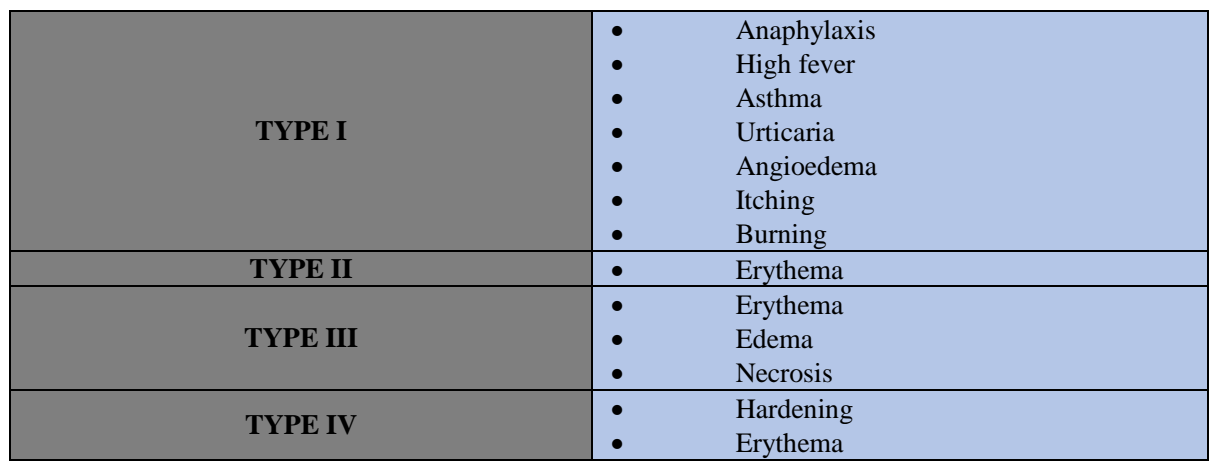

Table 2.Types of hypersensitivities and their associated clinical manifestations.

\begin{tabular}{|c|c|c|}
\hline Patient & Dose IM & Dose IV \\
\hline Adult & $\begin{array}{l}0.01 \mathrm{mg} / \mathrm{kg} \text { up to a maximum of } 0.5 \mathrm{mg} \\
\text { repeated every } 5-15 \mathrm{~min} \text { if necessary }\end{array}$ & $\begin{array}{l}0.75-1.5 \mu \mathrm{g} / \mathrm{kg}(\mathrm{ie}, 50-100 \mu \mathrm{g}) \text { for not } \\
\text { more than } 5 \text { minutes }\end{array}$ \\
\hline Children & $\begin{array}{l}-\quad \text { From } 6 \text { to } 12 \text { years: } 0.3 \mathrm{mg} \\
(0.3 \mathrm{ml} \text { in a } 1 / 1,000 \text { solution }) \\
-\quad 6 \text { months to } 6 \text { years: } 0.15 \mathrm{mg} \\
(0.15 \mathrm{ml} \text { in a solution of } 1 / 1,000) \\
-\quad \text { For children under } 6 \text { months } \\
0.1 \mathrm{mg}(0.1 \mathrm{ml} \text { in a } 1 / 1,000 \text { solution })\end{array}$ & $\begin{array}{l}0.75-1.5 \mu \mathrm{g} / \mathrm{kg}(\mathrm{ie}, 50-100 \mu \mathrm{g}) \text { for not } \\
\text { more than } 5 \text { minutes }\end{array}$ \\
\hline
\end{tabular}

Table 3. IM and IV doses of adrenaline in case of patient with allergic reaction.

\begin{tabular}{|c|l|l|l|}
\hline \multicolumn{1}{|c|}{ Hypersensitivity } & \multicolumn{1}{|c|}{ Duration of injury } & \multicolumn{1}{c|}{ Treatment } & \multicolumn{1}{c|}{ Considerations } \\
\hline TYPE I & $\begin{array}{l}\text { From 1 to 3 days, it solves } \\
\text { spontaneously }\end{array}$ & $\begin{array}{l}\text { Administer oral } \\
\text { antihistamines }\end{array}$ & $\begin{array}{l}\text { Avoid further contact } \\
\text { with the antigen }\end{array}$ \\
\hline TYPE III & $\begin{array}{l}\text { Develop quickly within 24 } \\
\text { hours }\end{array}$ & $\begin{array}{l}\text { Symptomatic, } \\
\text { mouthwash, } \\
\text { triamcinolone } \\
\text { acetonide or a } \\
\text { combination of them in } \\
\text { Orabase }\end{array}$ & $\begin{array}{l}\text { Avoid further contact } \\
\text { with the antigen }\end{array}$ \\
\hline TYPE IV & $\begin{array}{l}\text { Nature delayed, ask for } \\
\text { materials used 2-3 days } \\
\text { before }\end{array}$ & $\begin{array}{l}\text { Many times, not } \\
\text { necessary. If the } \\
\text { reaction is severe, } \\
\text { topical corticosteroids. } \\
\text { Removed the antigen }\end{array}$ & $\begin{array}{l}\text { Avoid further contact } \\
\text { with the antigen }\end{array}$ \\
\hline
\end{tabular}

Table 4.Types of hypersensitivity and their treatment options.

\section{Conclusions}

- The prevalence of intraoral contact allergy to dental materials appears to be relatively small.

- The clear majority of allergic reactions are type IV hypersensitivity reactions.

- For a material (metallic or not) to be responsible for some allergic manifestation, it is essential that it corrode and be released.

- There is no single or pathognomonic lesion of allergies.

- The allergic etiology may enter the differential diagnosis of many non-specific or unclear intraoral clinical pictures.

There are no acknowledgements.

\section{Acknowledgements}

\section{References}

[1]. Little J, Falace D, Miller C, Rhodus N. Dental Management of the Medically Compromised Patient. London: Elsevier Health Sciences; 2012.

[2]. Domínguez-Ortega J, Ruiz-Hornillos J, Chivato T, De la hoz B, Elices A, Iglesias A et al. La alergología en el sistema sanitario público de la Comunidad de Madrid: situación actual y oportunidades en el sistema sanitario público del siglo XXI. Anales del Sistema Sanitario de Navarra. 2014; 37(3):317-27.

[3]. Bhattacharya S. Anaphylactic Shock to Penicillin. Drug Safety. 2008:31(10):885-960.

[4]. Grace EG. Local Anaesthesia: Computerized local dental anesthetic systems: patient and dentist satisfaction. J Dent. 2003;195(2):83.

[5]. Urrutia I, Aguirre U, Sunyer J, Plana E. Cambios en la prevalencia de asma en la población española del Estudio de Salud Respiratoria de la Comunidad Europea (ECRHS-II). SPP. 2007;43(8):425-30.

[6]. Nel A, Diazsanchez D, Hiura T, Saxon A. Enhancement of allergic inflammation by the interaction between diesel exhaust particles and the immune system. J Allergy Clin Immunol. 1998;102(4):539-54. 
[7]. Schlosser B. Lichen planus and lichenoid reactions of the oral mucosa. Dermatologic Therapy. Am. J. Clin. 2010;23(3):251-267.

[8]. Ditrichova D, Kapralovab S, Tichya M, Tichac V, Dobesovaa J, Justovad E, Eberb M, Pirekb M. Oral lichenoid lesions and allergy to dental materials. Biomed Pap Med Fac Univ Palacky Olomouc Czech Repub. 2007, 151(2):333-339.

[9]. García-Peñín A, Guisado-Moya B, Montalvo-Moreno JJ. Riesgos y complicaciones de anestesia local en la consulta dental: Estado actual. RCOE. 2003;8(1) 41-63.

[10]. Brown AFT. Current management of anaphylaxis. Emergency 2009; 21: 213-23. 